\title{
Development of Taiwan Undergraduates' Volunteer Service Motivation Scale
}

\author{
Wu Ho-Tang ${ }^{1}$, Tu Chin-Tang ${ }^{2}$, Chou Mei-Ju ${ }^{3, *}$, Hou Jing-Fang ${ }^{4}$, Lei Meng-Shan ${ }^{1}$ \\ ${ }^{1}$ Department of Education, National Kaohsiung Normal University, Taiwan \\ ${ }^{2}$ Center for Teacher Education, National Kaohsiung University, Taiwan \\ ${ }^{3}$ Early Childhood Education and Center for Teacher Education, National Pingtung University, Taiwan \\ ${ }^{4}$ Kaohsiung Municipal Guochang Junior High School, Taiwan
}

Copyright $\mathrm{O} 2016$ by authors, all rights reserved. Authors agree that this article remains permanently open access under the terms of the Creative Commons Attribution License 4.0 International License

\begin{abstract}
This study aims to develop Taiwan undergraduates' volunteer service motivation scale. To begin with, item pool was proposed on the basis of literature. After discussing with three Taiwan undergraduates, item pool, exploratory factor analysis (EFA) $(N=150)$ was proceeded, where three tests were conducted EFA: 1. Item analysis: comparisons of extreme groups and correlation analysis were employed. The former's critical ratios are all more than 3, and reach significant standard, showing the 20 items have discriminating power. The latter shows that the $r$ value of all items and the total score are all more than .60 , and reach significant standard $(p<.001)$, showing the items can measure the same concept. 2. Factor analysis: primary axis factoring and the promax method of oblique rotation were adopted. In the first EFA, the 5 items concerning interpersonal relationship were distributed to other factors; and, due to incompatibility with other factors, so this dimension of Interpersonal Relationship was deleted. The 2nd EFA's results are consistent with the original design, which is categorized into Self-Growth, Serving Others, and Social Identification, and has appropriate total variation and total reliability. In order to verify the stability of the EFA factors, another batch of samples $(N=452)$ were investigated through confirmatory factor analysis (CFA). In accordance with the CFA's results, the initial model's test are acceptable without offending estimations, the basic fit of the initial model is in good fitness (including individual reliability, composite reliability, the average variance extracted, construct discrimination). To conclude, these 15 items 3 factors of Taiwan Undergraduates' Volunteer Service Motivation Scale has acceptable reliability and validity; therefore, it can serve as the scale to investigate Taiwan undergraduates' volunteer service motivation for proceeding the relative studies.
\end{abstract}

Keywords Taiwan Undergraduates, Volunteer Service, Motivation Scale

\section{Introduction}

Volunteer motivation can be defined as the drive of the individuals to seek for volunteer opportunities, commit themselves to voluntarily help, and sustain their involvement in volunteerism overextended periods of time (Pearce, 1983)[1]. Hustinx, Van Rossem, Handy and Cnaan (2015)[2] pointed out that motivation to volunteer is one of the most frequently researched topics in the field of volunteering research, which can be conducted in different occasions, like sports event (Farrell, Johnston, \& Twynam, 1998; Han, Quarterman, Strigas, \& Ha, 2013)[3][4], professional tennis event(Pauline \& Pauline, 2009)[5], professional golf event (Pauline, 2011)[6], festivals like food and wine festivals (Wu, Suh, \& Zhao, 2011)[7], Music Festival (Bachman, Backman, \& Norman, 2014)[8], not-for-profit organization like Phillips and Phillips (2010)[9]. In addition, volunteer service motivation is investigated extensively with other variables, such as organizational climate (Nencini, Romaioli, \& Meneghini, 2015)[10], job satisfaction (Bang, 2015)[11], commitment (de Espanés, Villar, Urrutia, \& Serrat, 2015)[12], sense of community (Kerwin, Warner, Walker, \& Stevens, 2015)[13], life satisfaction (Pierce, Johnson, Felver, Wanless, \& Judge, 2014 ;Veerasamy, Sambasivan, \& Kumar, 2015)[14][15], and the like, which can be seen clearly that volunteer service motivation is an issue worthy of our value.

From the above document, we can realize that Western put much emphasis on volunteer service motivation, and the situation happens in Taiwan as well. For example, Taiwan government encourages the public to engage in volunteer service, and 2001.1.20 published Volunteer Service Act [16] to integrate social human labor resources to be utilized to the utmost effect by those who intend to commit the 
national power to volunteer service to bring the virtue of volunteer service to a full play, foster each construction in the society, and raise the nationals' living quality. In addition, the citizens are encouraged to contribute to the society from their free will and sincere heart with knowledge, physical strength, labor, experience, technique, time, and etc. without the purpose of receiving remuneration to raise the efficacy of public affairs and promote each assistance-based service that enhance social welfare. This act also regulates the public schools to recruit, train, manage, exert, mentor, examine volunteer service personnel independently. At this point, the schools positively encourage the students to take part in volunteer service, which can provide the students with diversified learning experiences on one hand, and help them to obtain inner happiness and confirm the value of self from the process of helping others on the other hand. According to the Statistic Yearbook of Interior of Taiwan(Ministry of the Interior, 2012)[17], it shows that the total number of the students to participate in volunteer service is 32684, occupying $17.86 \%$ of the total number of people who engage in volunteer service. For the undergraduates, they are already adults who have more autonomy over their own behaviors, along with schoolwork pressures less than the senior high school students', so they have more time to serve others.

Due to plentiful undergraduates commit themselves to volunteer service in Taiwan region, their motivation is worthy of further survey. Nevertheless, such studies require a scale with validity and reliability to be used as the research tool. As far as the published articles are concerned, $\mathrm{Wu}(2005)$ [18] took 4812 undergraduates in 26 universities in Taiwan region as the research subject to analyze the motivation and factors of considerations of those who engage themselves in sport volunteer service. The research found that the order of the Taiwan undergraduates' motivations to participate in sport volunteer service are the feedback service, professional growth, self-challenges, and easy to learn. This scale is applied to volunteers in the sport situations, which can't be applied in general situation. As for this study, the purpose is to develop a scale suitable for any situations, so it has been re-developed so as to design an undergraduates' volunteer service motivation scale to be adopted by the relative studies.

\section{Literature Review}

To view from certain scales, there are various theoretical foundations for volunteer motivations, including functional approach, which refers that the individuals can be persuaded to volunteer through appeals to relevant psychological factors (Yoshioka, Brown, \& Ashcraft, 2007)[19]. Additionally, Clary, Snyder, Ridge, Miene, and Haugen (1994)[20] developed Voluntary Functions Inventory, which has proposed six different factors that exist in unique degrees of interest for each individual: (a) values (expressing deeply held beliefs about the importance of others); (b)social (conforming with the norms of significant others); (c) career (seeking for ways to get started or advance in the world of work); (d) understanding (engaging in activities that promote learning); (e) enhancement (enhancing one's sense of self-worth); and (f) protective (escaping negative feelings). Allison, Okun, and Dutridge (2002) [21] used this theory to develop Volunteer Functions Inventory as well, with the dimensions like career, esteem, protective, social, understanding, and value.

Another theoretical foundation is Self-Determination Theory (SDT), which Van den Broeck, Vansteenkiste, De Witte, Soenens, and Lens (2010)[22] developed Motivation at Work Scale-Revised, with dimensions including external regulation (four items, e.g., Because others put pressure on me"), introjected regulation (four items, e.g., "Because it makes me feel proud of myself"), identified regulation (four items, e.g., "Because what I do in this job has a lot of personal meaning to me"), integrated regulation (four items, e.g., "Because I am made for this type of work"), and intrinsic motivation (four items, e.g., "Because I enjoy this work very much"). In the same way, Geiser, Okun, \& Grano's (2014)[23] Motivation to Volunteer Scale involves those six dimensions as well.

Furthermore, Cognitive Evaluation Theory is also a sub theory of SDT, specifically addresses the social and environmental factors that facilitate rather than undermining intrinsic motivation, and points to three significant psychological needs that must be present in the individual in order to foster self-motivation, including competence, autonomy, and relatedness (Riley, 2015)[24].

The third theory, one of the early theories involving volunteer motivation, is Altruism, which conceptualizes altruistic motives (motivated to volunteer by concerns for the welfare of others) and Egoistic motives ( by self-interest, such as the desire to feel good about oneself) (Frisch \& Gerrard, 1981)[25].

Based on a thorough literature review on volunteer motivations, Cnaan and Goldberg-Glen's scale (1991) [26] was tested with direct service volunteers in human services to Motivation to Volunteer Scale. Meanwhile, on the basis of this scale, Farrell, Johntson, and Twynam (1998)[27] developed Special Event Volunteer Motivation Scale, followed by Grammatikopoulos, Koustelios, and Tsigilis (2006)[28] to develop Special Event Volunteer Motivation Scale for Greek Volunteers. Researchers like Giannoulakis, Wang, and Gray (2007) [29] all developed Olympic Volunteer Motivation with consultancy with Farrell et al's scale with the dimensions such as 1 . Purposive (indicate a desire to do something useful and contribute to the community and the event); 2 . Solidary (involve incentives related to social interaction, group identification, and networking); 3. External tradition (expresses motivations related to family traditions and the use of free time that can be seen as external influences on an individual's volunteer career); and 4. Commitments (contains incentives that link external expectations and personal skills with commitment 
to volunteering).

Synthesizing theories on volunteer participation and motivations, Fischer and Schaffer (1993) [30] proposed the following dimensions: altruistic motivation, ideological motivation (refers to dominated by the values), egoistic motivation (refers to behaviors are performed to secure personal gain or to avoid punishment)(Schroeder \& Graziano, 2015)[31], material/reward motivation, status/reward motivation, social relationship motivation, leisure time motivation, and personal growth motivation.

To sum up, different theoretical foundations lead to researchers' varied conclusions regarding the dimensions of volunteer motivation. Brown and Lehto (2005) [32] equally argued that no single motivational theory has yet fully connected with the hard facts of volunteer motivation consistently. In addition, the volunteer service motivations have not met the agreement. Since this study aims to develop a scale appropriate for the general undergraduates, the dimensions mainly concentrate on the universal motivations instead of applicability to a specific situation exclusively (like athlete meeting). Therefore, development of this scale adopts Fischer and Schaffer's (1993)[30] measures and synthesizes theories on volunteer's participation motivation and proposes four dimensions--personal growth, social identification, interpersonal relationships, and serving others. At last, according to the four dimensions, and with consultancy with the items in the abovementioned scales, the scale is transformed to what suit for the undergraduates' living situations.

\section{Methodology}

\section{(I). Pretest Questionnaire}

With the development of Volunteer Service Motivation Scale, the researches planed the first draft from the interview with three college students. According to the perspective of the college students, each item was discussed and revised for the design of pre-test questionnaire, as shown as Table 1 .

Table 1. Pre-test Questionnaire

\begin{tabular}{|c|c|c|c|}
\hline Dimension & Definition of Dimension & Items & Code \\
\hline \multirow{5}{*}{ Personal Growth } & \multirow{5}{*}{$\begin{array}{l}\text { Enrich the self. In addition to obtain } \\
\text { knowledge and skills, and try new things, } \\
\text { the undergraduates can extract social } \\
\text { experiences to foster the individuals to } \\
\text { become mature in personality and mind. }\end{array}$} & $\begin{array}{l}\text { 1. Enrich the self and foster the individuals to become mature in } \\
\text { personality and mind. }\end{array}$ & PG1 \\
\hline & & 2. Try new things and expand personal vision. & PG2 \\
\hline & & 3. Learn the skills and attitudes to deal with things. & PG3 \\
\hline & & 4. Obtain more knowledge and skills. & PG4 \\
\hline & & 5. Increase social experiences & PG5 \\
\hline \multirow{5}{*}{$\begin{array}{c}\text { Social } \\
\text { Identification }\end{array}$} & \multirow{5}{*}{$\begin{array}{l}\text { Hope to become the model in others' } \\
\text { mind, or due to social public's high } \\
\text { evaluation on the volunteers, one feels } \\
\text { needed, appreciated, and honor. }\end{array}$} & 6. Obtain others' identification & SI1 \\
\hline & & 7. Obtain others' praise and respect. & SI2 \\
\hline & & 8. Make oneself feel needed and valued. & SI3 \\
\hline & & 9. Become the model in others' mind. & SI4 \\
\hline & & 10. Make family and friends proud of oneself & SI5 \\
\hline \multirow{5}{*}{$\begin{array}{l}\text { Interpersonal } \\
\text { Relationships }\end{array}$} & \multirow{5}{*}{$\begin{array}{l}\text { Contact different people and things to } \\
\text { expand one's living circle and know more } \\
\text { friends, and therefore obtain sense of } \\
\text { belonging or subordination, and learn the } \\
\text { ability to interact with others. }\end{array}$} & 11. Popular when one provides service & IR1 \\
\hline & & 12.Know friends at different ages, expand the life circle & IR2 \\
\hline & & $\begin{array}{l}\text { 13. Make friends with who you can confide and share your } \\
\text { emotions and affection }\end{array}$ & IR3 \\
\hline & & 14. Learn the ability of communicating with others & IR4 \\
\hline & & $\begin{array}{l}\text { 15. Enhance human relationship, from which one receive love } \\
\text { and sense of belonging }\end{array}$ & IR5 \\
\hline \multirow{5}{*}{ Serving Others } & \multirow{5}{*}{$\begin{array}{l}\text { By personal power, one feedbacks to the } \\
\text { society and improve the society to } \\
\text { engage in the society more and obtain the } \\
\text { happiness of helping others. }\end{array}$} & 16. Spread love & SO1 \\
\hline & & 17. Obtain the happiness of helping others & $\mathrm{SO} 2$ \\
\hline & & 18. Devote oneself for others & $\mathrm{SO} 3$ \\
\hline & & 19. Solve problems for others & $\mathrm{SO} 4$ \\
\hline & & 20. Carry out social obligations and make contributions & $\mathrm{SO} 5$ \\
\hline
\end{tabular}




\section{(II). Research Sampling}

As to the sampling of survey group on Volunteer Service Motivation Scale, there are two surveys:

\section{(1) EFA Sample}

Since each dimension of this scale is designed based on literature, exploratory factor analysis (EFA) does not aim to recompose the item. Instead, it is to delete the wrongly placed items. For this sample $(N=150)$, Gender: Male $50(33.3 \%)$, female 100(66.7\%); Grade: Freshmen 29(19.3\%), Sophomore 34(22.7\%), Junior 30(20.0\%), Senior 57(38.0\%); Age: $M=20.78, S D=1.16$.

\section{(2) CFA Sample}

In order to verify the stability of the EFA factors, another batch of samples $(N=452)$ were surveyed through confirmatory factor analysis (CFA)-- Gender: 136 Males (30.1\%), 316 females (69.9\%); Grade: 107 Freshmen (23.7\%), 97 Sophomores (21.5\%), 75 Juniors (16.6\%), 172 Seniors $(38.1 \%)$; Age: $M=20.69, S D=1.21$.

\section{(3). Data Analysis}

This study focuses on the development of volunteer service motivation for university student. With EFA and CFA, this study tested on factor structural model and whether it meets the data we actually collected. Analysis was conducted with SPSS 16.0 for EFA (including item, factor and reliability analysis), and Amos 16.0 for CFA. (Including preliminary fit, overall model fit and fit of internal structural model).

\section{Results and Discussions}

To evaluate its psychometric properties, we responded to the Volunteer Service Motivation Scale to be analyzed in EFA and CFA.

\section{EFA Analysis}

After discussing with the three undergraduates on the first draft of the questionnaires item by item, it became the pretest questionnaires. In addition, it is found in the literature analysis that different theories would generate different dimensions. Also, different research subjects will cause difference in the dimensions. Consequently, EFA was adopted in this study to explore the factors. The procedures are as below:

\section{(I). Item Analysis}

On comparisons of extreme groups, the returned pretest questionnaires were summed up $(N=150)$, the first $27 \%$ of the total testes are called High Score Group $(n=41)$, while the last $27 \%$ are called Low Score Group $(n=42)$. For the results of independent sample $t$ test: $t$ value ranges between 5.49-9.14, with the critical ratio ( $t$ value) all are above 3 , reaching significant standard, and meaning that the 20 items have discriminative power. On correlation analysis, the results show that the $r$ values of all items and the total score range between .64-.81 and reach significant standard $(p<.001)$, showing that the items have medium and high correlation with that dimension, and that they can measure the same concept (McLever \& Carmines, 1981)[33]. In accordance with the results of comparisons of extreme groups and correlation analysis, 20 items are all retained.

\section{(II). Factor Analysis}

The results of item analysis show fit, so factor analysis was conducted for the 20 items in four dimensions. The procedures are listed below:

\section{(1) Test of KMO}

KMO value's (Kaiser-Meyer-Olkin measure of sampling adequacy) test result is .89 , presenting that the 20 items retained after item analysis fit to conduct factor analysis.

\section{(2) Factor Extraction and Orthogonal Rotation}

On factor extraction, the principle axis factoring was employed. Additionally, there is significant correlation between the four dimensions in the Volunteer Service Motivation Scale, and all relative coefficients reached .001 's significant standard, so promax method of oblique rotation was applied.

\section{(3) Factor Analysis}

The EFA was conducted. From the pattern matrix, it is found that the first factor is composed by Item 1-5 in Social Identification and Item 1, 3, and 5 in Interpersonal Relationships, the second factor is composed by Item 1-5 in Personal Growth and Item 2 and 7 in Interpersonal Relationships, and the third factor is composed by Item 1-5 in Serving Others. The 5 items in Interpersonal Relationships in the original design are dispersed to the first and second factors. Since the items in this dimension are not consistent with the content in other dimensions, the Dimension of Interpersonal Relationships has been deleted.

After deleting the Dimension of Interpersonal Relationships, the second EFA was conducted(see Table 2). The results meet the original design; among it, the first factor's (Personal Growth) eigenvalue is 8.18, and the explained variance amount is $52.73 \%$; The second factor's (Serving Others) eigenvalue is 2.30, and the explained variance amount is $13.44 \%$; and the third factor's (Social Identification) eigenvalue is 1.14 , and the explained variance is $72.16 \%$. The total explained variance is $72.16 \%$.

To conclude, the items in the second EFA factors are completely consistent with the literature, and the pattern coefficient ranges between .60-.92 (See Table 2). 
Table 2. Pattern matrix in the second EFA

\begin{tabular}{|c|c|c|c|c|c|c|c|c|c|}
\hline \multirow{2}{*}{ Item } & \multicolumn{3}{|c|}{$\begin{array}{c}\text { Component } \\
\text { (Pattern Matrix) }\end{array}$} & \multicolumn{3}{|c|}{$\begin{array}{c}\text { Component } \\
\text { (Structural Coefficient) }\end{array}$} & \multirow{2}{*}{ Commonality } & \multirow{2}{*}{$\begin{array}{c}\text { Explained } \\
\text { variance(\%) }\end{array}$} & \multirow{2}{*}{ Reliability } \\
\hline & 1 & 2 & 3 & 1 & 2 & 3 & & & \\
\hline PG 1 & 0.64 & 0.24 & 0.11 & 0.83 & 0.61 & 0.67 & 0.74 & 52.73 & .92 \\
\hline PG 2 & 0.84 & -0.12 & 0.11 & 0.86 & 0.36 & 0.65 & 0.76 & & \\
\hline PG 3 & 0.90 & 0.08 & -0.10 & 0.87 & 0.49 & 0.58 & 0.77 & & \\
\hline PG 4 & 0.70 & 0.09 & 0.05 & 0.78 & 0.46 & 0.59 & 0.61 & & \\
\hline PG 5 & 0.93 & -0.12 & -0.09 & 0.81 & 0.31 & 0.52 & 0.67 & & \\
\hline SI 1 & 0.13 & 0.77 & -0.06 & 0.47 & 0.80 & 0.40 & 0.65 & 13.44 & .91 \\
\hline SI 2 & -0.03 & 0.96 & -0.15 & 0.35 & 0.88 & 0.29 & 0.79 & & \\
\hline SI 3 & 0.14 & 0.66 & 0.04 & 0.50 & 0.75 & 0.45 & 0.58 & & \\
\hline SI 4 & -0.07 & 0.87 & 0.11 & 0.45 & 0.89 & 0.48 & 0.79 & & \\
\hline SI 5 & -0.13 & 0.81 & 0.09 & 0.34 & 0.79 & 0.38 & 0.63 & & \\
\hline SO 1 & -0.19 & 0.10 & 0.97 & 0.55 & 0.47 & 0.88 & 0.80 & 5.99 & .93 \\
\hline SO 2 & 0.06 & -0.02 & 0.86 & 0.66 & 0.42 & 0.90 & 0.80 & & \\
\hline SO 3 & 0.02 & -0.05 & 0.90 & 0.64 & 0.39 & 0.90 & 0.81 & & \\
\hline $\mathrm{SO} 4$ & 0.36 & -0.10 & 0.61 & 0.75 & 0.37 & 0.82 & 0.74 & & \\
\hline SO 5 & 0.39 & 0.07 & 0.46 & 0.75 & 0.48 & 0.77 & 0.68 & & \\
\hline & & \multicolumn{2}{|c|}{$\begin{array}{c}\text { Total explained } \\
\text { variance amount }\end{array}$} & $\begin{array}{l}\text { And Total } \\
\text { reliability }\end{array}$ & & & & 72.16 & .94 \\
\hline
\end{tabular}

Note: 1. Extraction method: the principle axis factoring. Rotation: Promax method containing normalized Kaiser. 2. The bold font in the Table signifies the factor that the items belong to.

\section{(III). Reliability Analysis}

The remaining 15 items after the second factor analysis was conducted for reliability analysis, The Cronbach's $\alpha$ coefficient of Personal Growth, Serving Others, and Social Identification are $.92, .91$, and .93 , respectively, and the total reliability is .94 , showing that both the dimensions and the overall meet the standard of .80 , and the items possess stability.

\section{CFA Analysis}

(I). Product Moment Correlation between the Three Latent Variables in the Volunteer Service Motivation Scale

Table 3. Product Moment Correlation and Descriptive Data of the three Latent Variables in the Volunteer Service Motivation Scale

\begin{tabular}{|c|c|c|c|c|c|}
\hline Item and No. & $\mathbf{1}$ & $\mathbf{2}$ & $\mathbf{3}$ & $\mathbf{M}$ & SD \\
\hline 1. Personal Growth & 1 & & & 20.47 & 3.22 \\
\hline 2. Serving Others & $.71^{* * *}$ & 1 & & 20.30 & 3.69 \\
\hline 3. Social Identification & $.46^{* * *}$ & $.49^{* * *}$ & 1 & 16.45 & 4.55 \\
\hline
\end{tabular}

$* * * p<.001$.

The remaining 15 items after EFA were compiled into the formal questionnaires. On the other hand, 452 undergraduates were investigated additionally. After investigation, the dimensions and the total score were summed up for product moment correlation, and the results show that the correlation between the three latent variables ranges between .46-.71 (see Table 3), reaching significantly positive correlation $(p<.001)$.

\section{(II). CFA}

(1) The Test for the Preliminary Model

The CFA test results are shown in Fig. 1: In regard of the overall fitness of the preliminary model, $\chi^{2}=360.33$, degree of freedom $=87, p=.00$, RMSEA $=.08$, AGFI $=.87$, TLI $=.93, \mathrm{CFI}=.94, \chi^{2}$ reaches significant standard, so it does not meet the standard. Since $\chi^{2}$ tends to be affected by the number of samples, the value is for consultancy only. In addition, the smaller the RMSEA, the better the fitness is. In this study, the value is .08 , meeting the standard. Also, TLI and CFI meet the standard of .90. Regarding AGFI, Anderson and Gerbing (1984) [34] claimed that AGFI $\geq 0.80$. From the analysis above, it is learned that the preliminary model is acceptable. 


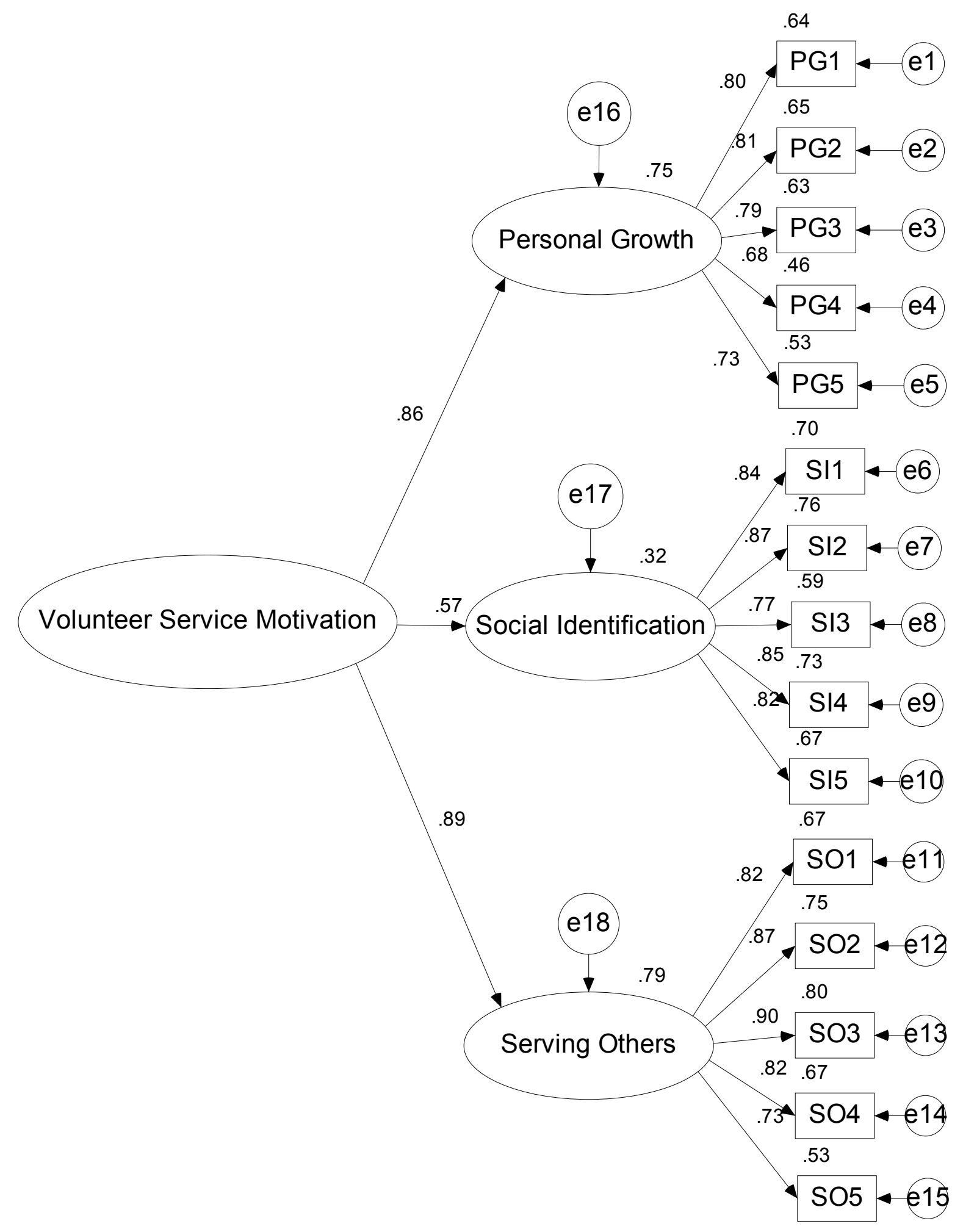

Note: data over the observation index is the individual reliability

Figure 1. The test results of the preliminary model (standard solution)

(2) The Basic Fitness

The findings from the basic fitness analysis are: 1 . In the $\Theta_{\varepsilon}$ matrix components, the error variances from $\varepsilon_{1}$ to $\varepsilon_{15}$ are all positives; 2 . the $t$ values of all error variances ranges between 10.21-13.63, and reached significant standard of more than $.01 ; 3$. the standard error of the parameters ranges between $.04-.11$ without extremely large standard errors; 4 . the factor loading $\left(\lambda_{1}-\lambda_{15}\right)$ between the latent variables and the measuring indicators ranges between .68-.90, complying with the standard of more than .50 and less than .95 . 
Bagozzi and Yi (1988)[35] hold that the higher the factor loading, the more it can reflect the extent of the latent variable. Also, Hair, Anderson, Tatham, and Black (1998) [36] considered that high factor loading represents the items possess good convergent validity.

It is found that the results of the preliminary model's basic fitness analysis meet the four basic fitness indicators. That is to say, as a whole, the basic fitness of the preliminary model is good, without what Hair et al (1998) [36] called offending estimates (refer to the output data does not exceed the acceptable range). All test results comply with the basic fitness, showing good item quality.

\section{(3) Analysis of the Fitness of the Internal Structure}

In regard of the individual reliability, the 15 observation indicators" individual reliability ranges between $.46-.80$, only "PG4" does not comply with the standard of .50. Bollen (1989) [37] indicated that the latent variables' individual observation indicator must possess considerable reliability, or the model will not be supported. Bagozzi and Yi (1988)[35] pointed out that the individual reliability should exceed .50 to show that the items have ideal quality. Among the individual reliability of the 15 observation indicators, only one does not meet the standard, but the other 14 do.

Regarding the composite reliability, the composite reliability of the three latent variables are Personal Growth .88, Social Identification .91, and Serving
Others .92. The three latent variables all meet the standard of more than .60, which also shows that the measuring indicator of the three variables can detect more than $88 \%$ of the latent construct.

In regard of the average variance extraction amount, that of the three latent variables are Personal Growth .59, Social Identification .69, and Serving Others .69, all meeting the standard of more than .50 . The average variance extraction amount reflects the indicator of the convergent degree that can effectively estimate the latent variable with the observation indicator (Fornell \& Larcker, 1981)[38]. In the Scale of this study, the three variables meet the standard of more than .50 , signifying that the observation variable can sufficiently reflect the constructed latent variables.

Concerning the construct discriminative power, this study adopts the competition model comparison method (Anderson \& Gerbing, 1984)[34]. From Table 4, it can be perceived that the $\chi^{2}$ value's difference amount between the three restricted model and un-restricted models are 139.13, 105.66, and 116.15, which are all more than the threshold indicator $3.84(p<.05)$. In other words, the chi square value's difference amount between the three restricted model and non-restricted models achieves the significant standard of .05, so the hypothesis that any two paired latent variables' correlation is complete correlation $(\rho=1)$ can-not be established. In the Scale, there is significant difference in the potential property shown between the three latent variables (factor constructs).

Table 4. Summary of analysis of construct's discriminative power in the Volunteer Service Motivation Scale

\begin{tabular}{|c|c|c|c|c|c|c|c|}
\hline \multirow{2}{*}{ Paired Latent Variables } & \multicolumn{3}{|c|}{ Restricted model (B) } & \multicolumn{3}{c|}{ Un-restricted Model (A) } & $\begin{array}{c}\chi^{2} \\
\text { Difference(B-A) }\end{array}$ \\
\cline { 2 - 9 } & $\rho 1$ & df & $\chi^{2}$ & $\rho$ & df & $\chi^{2}$ & $\Delta \chi^{2}$ \\
\hline Personal Growth_Social Identification & 1 & 35 & 343.81 & .49 & 34 & 204.68 & $139.13^{*}$ \\
\hline Personal Growth_Serving Others & 1 & 35 & 247.01. & .77 & 34 & 141.32 & $105.66^{*}$ \\
\hline Serving Others_Social Identification & 1 & 35 & 318.73 & .50 & 34 & 202.58 & $116.15^{*}$ \\
\hline
\end{tabular}

Note: * signifies that the chi square value of the restricted model and the un-restricted model are all larger than 3.84 , reaching the significant standard of .05 . 


\section{Discussions}

This study aims to develop Taiwan undergraduates' Volunteer Service Motivation Scale, which process started with reading the relative literature. From the literature, it is found that volunteer motivation has different theoretical foundations, such as functional approach that Clary et al. (1994)[19] used to develop Voluntary Functions Inventory, or Allison et al (2002) [20]used to develop Volunteer Functions Inventory. Besides, Self-Determination Theory was also utilized by Van den Broeck et al (2010)[21] in Motivation at Work Scale-Revised and by Geiser et al (2014)[22] in the Motivation to Volunteer Scale. Other theoretical foundations include cognitive evaluation theory and altruism, and comprehensive volunteer participation motivation of Fischer and Schaffer (1993)[30]. On the basis of the scales developed by such theories, it is observed that different theoretical foundations lead to inconsistent dimensions, which explains that the dimensions of volunteer service motivation do not meet the consensus. Consequently, this study tries to take into considerations of Taiwan undergraduates' living situation, and select Personal Growth, Social Identification, Interpersonal Relationships, and Serving Others as the Dimensions. Meanwhile, it consulted the scales described above to make the first draft of the 20 items.

Next, after discussing with three college students on the first draft item by item, EFA was conducted through three steps: 1. Item Analysis: the critical value and correlation coefficient of the 20 items meet the standard, showing that the items have discriminative power; 2. Factor Analysis: In the first EFA analysis, three items in Interpersonal relationships combine with the first factor, Social Identification, while two items of Interpersonal relationships integrate with the second factor, Personal Growth. That is, 5 items of Interpersonal relationships in the original design are dispersed to the first and the second factors. Since the items in the dimension of Interpersonal relationships is not consistent with the content of other dimensions, it was deleted. When Clary et al (1998)[39] developed Voluntary Functions Inventory, similar condition occurred. For example, "Volunteering is a way to make new friends" was integrated with the understanding factor (refer to engaging in activities that promote learning).

After deleting the Dimension of Interpersonal relationships, the second EFA was conducted. The results meet the original design, where the first factor is Personal Growth (5 items), the second is Serving Others (5 items), and the third is Social Identification (5 items). The items collected in the factors in the second EFA comply with the literature completely, have fair reliability and validity, and meet the ideal item number of 5-7 as claimed by Bollen(1989)[37].

Finally, regarding the stability of the 15 items of the three factors obtained from EFA, we verified the 15 items with CFA, and found that: the overall fitness is acceptable, the basic fitness is good, and the internal structure's fitness is acceptable. To conclude, the CFA results are aligned with EFA results, which demonstrate that the Volunteer Service Motivation Scale with three factors' 15 items is stable. Therefore, the results in this study is consistent with Brown and Lehto (2005) [32], for they argued that no single motivational theory has yet fully connected with the hard facts of volunteer motivation consistently. In addition, they also support the research of developing scale with synthesizes theories by Fischer and Schaffer's (1993) [30].

Above all, Volunteer Service Motivation Scale with three factors' 15 items is stable; furthermore, compared with Chinese version scale, such as the research by $\mathrm{Li}, \mathrm{Wu}$, and Kee(2016)[40] adopting SDT to develop Volunteer Motivation Scale for Chinese undergraduate students, the initial item pool of the VMS-C with 18 items measuring six motivation types was administrated to Chinese volunteers $(N=362)$ Factor analysis led to a five-factor model( intrinsic motivation, identified regulation, introjected regulation, external regulation and amotivation) with 15 items. 15 items loaded cleanly onto the target factors with each factor having three items. Their factor loading ranged from 0.46 to 0.82 ; while the research adopted synthesizes theories, and its constructed numbered item is similar, and there are only three factors within this research scale. Furthremore, Wu, Lo, and Liu (2009) adopted [41] functional approach to develop Chinese version of the Volunteer Functions Inventory, its samples were 279 students at the City University of Hong Kong, EFA. From its results, we get six factors including Protective, Values, Career, Social, Understanding, and Enhancement, and each factor included five items, the internal consistency (Cronbach á) ranged from .70 to .91. All consistent for the standard of .60 above. And the Cronbach á's ranged in this research is from $.91-93$, total á $=.94$, which means it has high internal consistency.

\section{Conclusions and Suggestions}

In accordance with literature, the undergraduates' Volunteer Service Motivation Scale was proposed. After EFA and CFA analysis, it shows that three factors-Personal Growth, Serving Others, and Social Identification-- have acceptable reliability and validity. Consequently, this Scale can be exerted as one used to investigate Taiwan undergraduates' Volunteer Service Motivation Scale to proceed relative studies.

In addition, from the literature, it has been found that volunteer motivation is supported by different theoretical foundations that result in different dimensions, like functional approach, cognitive evaluation theory, and altruism. On the other hand, there are comprehensive theories that lead to different dimensions of the scale. Furthermore, the development of certain scales aims at specific situation (like athlete meeting). As in this study, the Scale does not aim at particular situation; instead, it focuses on the universality. As a result, it is recommended that the studies in the future can develop scales suitable for a variety 
of situations on the foundation of a single theory.

\section{REFERENCES}

[1] J. L. Pearce, Job attitude and motivation differences between volunteers and employees from comparable organizations. Journal of Applied Psychology, Vol: 68, No. 4, 646-652, 1983.

[2] L. Hustinx, R. Van Rossem, F. Handy, R. A. Cnaan, A cross-national examination of motivation to volunteer: religious context, national value patterns, and nonprofit regimes. Religion and volunteering: complex, contested and ambiguous relationships, 2015. Retrieved from https://biblio.ugent.be/publication/4269575

[3] J. M. Farrell, M. E. Johnston, G. D. Twynam, Volunteer motivation, satisfaction, and management at an elite sporting competition. Journal of Sport Management, Vol:12, No. 2, 288-300, 1998.

[4] K. Han, J. Quarterman, E. Strigas, J. Ha, Committed sport event volunteers. The ICHPER-SD Journal of Research in Health, Physical Education, Recreation, Sport \& Dance, Vol: 8, No. 2, 45-54, 2013.

[5] G. Pauline, J. S. Pauline, Volunteer motivation and demographic influences at a professional tennis event. Team Performance Management: An International Journal, Vol: 15, No. 3/4, 172-184, 2009.

[6] G. Pauline, Volunteer satisfaction and intent to remain: An analysis of contributing factors among professional golf event volunteers. International Journal of Event Management Research, Vol: 6, No. 1, 10-32, 2011.

[7] H. Wu, E. Suh, J. Zhao, An exploratory study of hospitality student volunteers' motivation and satisfaction in food and wine festivals, 2011. Retrieved from http://scholarworks.um ass.edu/gradconf_hospitality/2011/Poster/143/.

[8] J. R. Bachman, K. F. Backman, W. C. Norman, A segmentation of volunteers at the 2013 Austin City Limits Music Festival: Insights and future directions. Journal of Convention \& Event Tourism, Vol: 15, No. 4, 298-315, 2014.

[9] L. C. Phillips, M. H. Phillips, Volunteer motivation and reward preference: An empirical study of volunteerism in a large, not-for-profit organization. SAM Advanced Management Journal, Vol: 75, No. 4, 12-39, 2010.

[10] A. Nencini, D. Romaioli, A. M, Meneghini, Volunteer motivation and organizational climate: Factors that promote satisfaction and sustained volunteerism in NPOs. VOLUNTAS: International Journal of Voluntary and Nonprofit Organizations, 1-22, 2015.

[11] H. Bang, Volunteer age, job satisfaction, and intention to stay: a case of nonprofit sport organizations. Leadership \& Organization Development Journal, Vol: 36, No. 2, 161-176, 2015.

[12] G. M. de Espanés, F. Villar, A. Urrutia, R. Serrat, Motivation and Commitment to Volunteering in a Sample of Argentinian Adults: What is the Role of Generativity? Educational Gerontology, Vol: 41, No.2, 149-161, 2015.
[13] S. Kerwin, S. Warner, M. Walker, J. Stevens, Exploring sense of community among small-scale sport event volunteers. European Sport Management Quarterly, Vol: 15, No. 1, 77-92, 2015.

[14] D. Pierce, J. Johnson, N. Felver, E. Wanless, L. Judge, Influence of Volunteer Motivations on Satisfaction for Undergraduate Sport Management Students. Global Sport Business Journal, Vol: 2, No. 2, 63-72, 2014.

[15] C. Veerasamy, M. Sambasivan, N. Kumar, Life satisfaction among healthcare volunteers in Malaysia: Role of personality factors, volunteering motives, and spiritual capital. VOLUNTAS: International Journal of Voluntary and Nonprofit Organizations, Vol: 26, No. 2, 531-55, 2015.

[16] Taiwan Volunteer Service Act(2001).

[17] Ministry of the Interior, Statistic yearbook of interior. Taipei, Taiwan: Author, 2012.

[18] H. C. Wu, A study of motivation and consideration criteria for sport volunteers among college students in Taiwan. Physical Education Journal, 38(4), 93-107, 2005.

[19] C. F. Yoshioka, W. A. Brown, R. F. Ashcraft, A functional approach to senior volunteer and non-volunteer motivations. The international journal of volunteer administration, Vol: 24, No. 5, 31-43, 2007.

[20] E. G. Clary, M. Snyder, R. D. Ridge, P. K. Miene, Haugen, J. A., Matching messages to motives in persuasion: A functional approach to promoting volunteerism. Journal of Applied Social Psychology, Vol: 24, 1129-1149, 1994.

[21] L. D. Allison, M. A. Okun, K. S. Dutridge, Assessing volunteer motives: a comparison of an open - ended probe and Likert rating scales. Journal of Community \& Applied Social Psychology, Vol: 12, No. 4, 243-255, 2002.

[22] A. Van den Broeck, M. Vansteenkiste, H. De Witte, B. Soenens, Lens, W., Capturing autonomy, competence, and relatedness at work: Construction and initial validation of the Work-Related Basic Need Satisfaction Scale. Journal of Occupational and Organizational Psychology, Vol: 83, 981-1002, 2010.

[23] C. Geiser, M. A. Okun, Grano, C., Who is motivated to volunteer? A latent profile analysis linking. Volunteer motivation to frequency of volunteering. Psychological Test and Assessment Modeling, Vol: 56, No. 1, 3-24, 2014.

[24] G. Riley, Differences in Competence, Autonomy, and Relatedness between Home Educated and Traditionally Educated Young Adults. International Social Science Review, Vol: 90, No. 2, 1-26, 2015.

[25] M. B. Frisch, M. Gerrard, Natural helping systems: Red Cross volunteers. American Journal of Community Psychology, Vol: 9, 567-579, 1981.

[26] R. Cnaan, R. S. Goldberg-Glen, Measuring motivation to volunteer in human services. Journal of Applied Behavioral Science, Vol: 27, 269-284, 1991.

[27] J. M. Farrell, M. E. Johnston, D. Twynam, Volunteer motivation, satisfaction, and management at an elite sporting competition. Journal of Sport Management, Vol: 12, 288-300, 1998.

[28] V. Grammatikopoulos, A. Koustelios, N. Tsigilis, Construct 
validity of the Special Event Volunteer Motivation Scale for Greek Volunteers. Leisure/Loisir, Vol: 30, No. 1, 287-305, 2006.

[29] C. Giannoulakis, C. H. Wang, D. Gray, Measuring volunteer motivation in mega-sporting events. Event Management, Vol: 11, No. 4, 191-200, 2007.

[30] L. R. Fischer, K. B. Schaffer, Older volunteers: A guide to research and practice. Thousand Oaks, CA: Sage, 1993.

[31] D. A. Schroeder, W.G. Graziano, The field of prosocial behavior: An introduction and overview. In D. A. Schroeder \& W. G. Graziano (Eds.), The Oxford handbook of prosocial behavior (pp. 3-34). Oxford, UK: Oxford University, 2015.

[32] S. Brown, X. Lehto, Travelling with a purpose: Understanding the motives and benefits of volunteer vacationers. Current Issues in Tourism, Vol: 8, No. 6, 479496, 2005

[33] J. P. McIver, E. G. Carmines, Unidimensional scaling. Thousand Oaks, CA: Sage, 1981.

[34] J. C. Anderson, D. W. Gerbing, The effect of sampling error on convergence, improper solutions and goodness-of-fit indices for maximum likelihood confirmatory factor analysis. Psychometrika, Vol: 49, 155-173, 1984.

[35] R. P. Bagozzi, Y. Yi, On the evaluation of structural equation models. Academic of Marketing Science, Vol: 16, 74-94, 1988.

[36] J. F. Hair, R. E. Anderson, R. L. Tatham, W. C. Black., Multivariate data analysis (5th ed.). Englewood Cliffs, NJ: Prentice-Hall, 1998.

[37] K. A. Bollen, Structural equations with latent variables. New York, NY: Wiley \& Sons, 1989.

[38] C. Fornell, D. F. Larcker, Evaluating structural equation models with unobservable variables and measurement error. Journal of marketing research, Vol: 18, 39-50, 1981.

[39] E. G. Clary, M. Snyder, R. D. Ridge, J. Copeland, A. A. Stukas, J. Haugen, P. Miene, Understanding and assessing the motivations of volunteers: a functional approach. Journal of personality and social psychology, 74(6), 1516-1530, 1998.

[40] C. Li, Y. Wu, Y. H. Kee, Validation of and its relations with work climate and intention among Chinese volunteers. Asian Journal of Social Psychology, 2016. Retrieved from http://onlinelibrary.wiley.com/doi/10.1111/ajsp.12127/pdf

[41] J. Wu, T. W. Lo, E. S. C. Liu, Psychometric properties of the Volunteer Functions Inventory with Chinese students. Journal of Community Psychology, Vol: 37, No. 6, 769-780, 2009. 